\title{
Proceso de certificación de calidad y exportación del café en exportadora ATLANTIC S.A. Periodo 2012-2013 ${ }^{1}$
}

\section{The process of quality certification and coffee export in the ATLANTIC SA Exporter. Period 2012-2013}

\author{
Mayra Daniela Ruiz Cornejo² \\ Heyling Jolibeth López Rodríguez ${ }^{3}$ \\ Yeslin Yohenia Pérez Ochoa ${ }^{4}$
}

1 Este artículo se elabora a partir de la tesis titulada Proceso de Certificación de calidad y Exportación del café en Exportadora ATLANTIC S.A. Periodo 2012-2013. Para optar al título de administración de empresas en el año 2013 por la UNANManagua, FAREM-Estelí

2 UNAN-Managua, FAREM-Estelí. Correo Electrónico: ruizmayradaniela@yahoo.com

3 UNAN-Managua, FAREM-Estelí. Correo Electrónico: lrheyling@yahoo.es

4 UNAN-Managua, FAREM-Estelí. Correo Electrónico: yeslinperez8a@yahoo.es

\section{RESUMEN}

El presente trabajo se enfoca en el Proceso de Certificación de calidad y Exportación del café en Exportadora ATLANTIC S.A para el diseño de una estrategia que mejore la relación de la empresa con los productores, de forma que se asegure la calidad del café exportable. Según el nivel de conocimiento esta investigación es aplicada y según el enfoque filosófico es cualitativa. La muestra la constituye Exportadora ATLANTIC con sede central en la ciudad de Managua y sus tres oficinas regionales ubicadas en Matagalpa, Jinotega y Ocotal. Las técnicas de recolección de datos utilizadas fueron: investigación documental, observación y entrevistas. Las entrevistas se aplicaron a informantes claves de la empresa con amplio conocimiento en Certificación y Exportaciones y a productores con un mínimo de 2 años produciendo café certificado.

Los principales resultados reflejan el proceso de certificación de calidad y exportación de café al mercado diferenciado bajo diferentes sellos de certificación y se describen los requisitos que exigen estos sellos para asegurar la trazabilidad del café en las etapas de producción, procesamiento y comercialización. Así mismo, se hace referencia a las actuales dificultades que presenta la empresa para comercializar el café certificado.

Palabras claves: Certificación, Calidad, Exportación, Mercado diferenciado.

\section{ABSTRACT}

This study focuses on the process of quality certification and coffee export in the ATLANTIC SA Exporter to design a strategy to improve the company's relationship with the producers, so that the quality of exportable coffee is ensured. According to the level of knowledge this research is applied and as the philosophical approach is qualitative.

The sample is the Exporting ATLANTIC headquartered in the city of Managua and three regional offices located in Matagalpa, Jinotega and Ocotal. The data collection techniques used were: documentary research, observation and interviews. The interviews were 
held with key informants in company with extensive knowledge and Export Certification and producers with a minimum of 2 years producing certified coffee.

The main results reflect the quality certification process and export of coffee a distinct market under different labels and certification requirements that require these seals to ensure traceability of coffee in the stages of production, processing and marketing are described.

Keywords: Certification, Quality, Export, Market differentiated.

\section{INTRODUCCIÓN}

Exportadora del ATLANTIC S.A es una empresa miembro del grupo ECOM fundada el 11 de Junio de 1997 de conformidad con las leyes de la República de Nicaragua. Nace como iniciativa de varios productores de Matagalpa y Jinotega con el fin de integrarse en la exportación, entender mejor el mercado y mejorar su proyección internacional.

La producción de café en el ciclo $2012-2013$ se vio afectada por diversos factores, entre ellos el cambio climático que provocó la expansión de la roya en un $32 \%$ sobre las plantaciones de café a nivel nacional, por esta razón bajó la calidad del café que los productores entregan a la exportadora y disminuyó la cantidad de café oro exportado por esta empresa a los mercados internacionales. Otro factor que influye en la calidad del café, es el manejo que los productores dan a sus cafetales, existen muchas enfermedades que afectan el desarrollo y la calidad del café, entre las más comunes están: la roya, broca, ojo de gallo, antracnosis y mal de hilacha, las cuales pueden ser tratadas y prevenidas a través del buen mantenimiento de los cafetales. Para asegurar la calidad del café ATLANTIC tiene un equipo técnico que capacita a los productores, no obstante la puesta en marcha de las instrucciones depende de la capacidad económica del productor para invertir y del interés que éste tenga en mejorar la productividad de su finca.
Se revisaron diversas fuentes de información relacionadas al tema de investigación, pero no se encontraron investigaciones que presenten un estudio sistemático y completo sobre la Exportadora. Díaz (2009), realiza una investigación titulada "Comercialización de productos mediante la Técnica de Microprogramación Embriogénesis Somática en el cultivo del café por el Laboratorio Exportadora ATLANTIC, S.A reflejando que la técnica de micropropagación embriogénesis somática es un aporte a la caficultura nacional y cuenta con nichos de mercado potenciales en la zona norte del país, Centroamérica y México, permitiendo una mayor expansión comercial y aumento necesario de la capacidad productiva. Castillo (2011), realiza una investigación titulada: "Comercialización y Calidad para la aceptación del café orgánico en el mercado internacional de la Unión de Cooperativas de Servicios Múltiples del Norte R.L. (UCOSEMUN R.L). Refleja que para la empresa alcanzar un alto grado de calidad está en dependencia de los caficultores y del responsable del control de calidad. Una de las problemáticas identificadas es que la empresa no cuenta con un canal de comercialización directo. Lanzas (2011), realiza una investigación titulada: "Proceso de Certificación para la exportación de café orgánico en la Cooperativa UCPCO San Juan del Río. Esta investigación refleja que para obtener la certificación, el productor debe cumplir con los requisitos presentados por la agencia certificadora, siendo una garantía de que el café se manejó siguiendo las normas de producción orgánica.

El presente estudio contiene un análisis de las principales Fortalezas, Oportunidades, Debilidades y Amenazas que enfrenta ATLANTIC para proponer estrategias que generen oportunidades de desarrollo a la empresa, las cuales sirven de guía para que los gerentes tomen decisiones encaminadas a mejorar los proceso de certificación y exportación. 
El estudio de esta temática sirve de retroalimentación a los productores que implementan el proceso de certificación en sus fincas, ya que se les da a conocer las oportunidades de la certificación para que apliquen correctamente los requisitos de éste proceso que además de generarles una visión empresarial, les proporciona beneficios en el desarrollo y productividad de las fincas, mejorando así la comercialización del café realizada por ATLANTIC. El desarrollo de ésta investigación también proporciona información a los productores que todavía no trabajan bajo el proceso de certificación para que conozcan la importancia de cultivar y entregar un café de calidad que los beneficie en su desarrollo económico y en la productividad de sus fincas.

Como objetivo principal se planteó analizar el proceso de certificación de calidad y exportación del café de Exportadora ATLANTIC, S.A para el diseño de una estrategia que mejore las relaciones de la empresa con los productores de forma que se asegure la calidad del café exportable.

Como base conceptual para esta investigación se definieron cuatro ejes teóricos: Empresa, mercado diferenciado, producción y exportación de café. Para Navas (2008), la empresa desde el punto económico es la organización de los factores de la producción tendiente a la producción de bienes o servicios o al cambio de estos mismos. Con lo primero queda comprendida toda actividad industrial, con lo segundo queda comprendida toda actividad comercial en sentido económico, en sentido estricto. (p. 30).

El mercado diferenciado comprende la creación de diferencias en la oferta de productos de la empresa que la distinguen de la oferta de la competencia. Por lo general, esta diferenciación se basa en diferentes características de productos, servicios adicionales $u$ otras características (Ferrell, 2006).
Según la Asociación Nacional del Café, el proceso de producción del café es la transformación del fruto de café maduro a café pergamino seco de punto comercial, a través de las siguientes etapas: Recolección del fruto, despulpado, lavado manual, fermentación y secado.

De acuerdo a la Ley 368 la exportación de café es toda salida del territorio aduanero del país, de café en oro o cualquier estado más avanzado de procesamiento en que se encuentre, cuya clase, tipo, calidad y peso de embarque corresponden al declarado en el contrato respectivo y amparado en los formatos respectivos de exportación. (MIFIC).

\section{MATERIALES Y MÉTODOS}

Según el nivel de conocimiento esta investigación es aplicada porque se va a estudiar la problemática sobre el proceso certificación de calidad y exportaciones de Exportadora ATLANTIC, S.A y se desarrollan estrategias para reducir los cuellos de botella que se generan en la certificación y exportación del café. Según el enfoque filosófico es una investigación cualitativa porque se analiza a profundidad el proceso de certificación y exportación y se determinan los diversos aspectos que intervienen en dichos procesos.

El universo de esta investigación lo constituye la Exportadora ATLANTIC, S.A, con sede central en la ciudad de Managua, y sus tres oficinas regionales ubicadas en Matagalpa, Jinotega y Ocotal. El muestreo es no probabilístico, porque no todo el universo tiene la misma probabilidad de ser seleccionado. Para seleccionar la muestra se definieron los siguientes criterios: 1) Informantes claves en la empresa, con amplio conocimiento en Certificación y Exportaciones (Gerente regional, Coordinadora de tráfico, Coordinador de Sostenibilidad); 2) Disposición de los informantes claves a ser entrevistados y participación de manera voluntaria en el estudio; y 3) Productores de Exportadora ATLANTIC que tengan 2 años de producir café certificado. 
Para cumplir con los objetivos planteados en la investigación, se utilizaron tres técnicas de recolección de datos: Investigación documental, entrevista semiestructurada y guía de observación.

\section{RESULTADOS Y DISCUSIÓN}

\section{CERTIFICACIÓN DEL CAFÉ}

La certificación es un proceso de sostenibilidad que incluye buenas prácticas agrícolas en las fincas, responsabilidad social empresarial, cumplimiento de leyes, normativas, mejoras continuas en las fincas y oportunidad de mercado en el mundo del café. Todas estas variables en su conjunto son una herramienta de diferenciación del café para el consumidor. El Ingeniero Luis Lanzas, Coordinador de Sostenibilidad a nivel nacional explicó:

"La certificación para la empresa es una necesidad y una oportunidad de mercado, es una estrategia de negocio, porque a nivel mundial los consumidores quieren café certificado, entonces hay que certificar más café para tener acceso a esos mercados. Es un sistema de administración de fincas, donde manejamos las fincas apropiadamente bajo los tres pilares de sostenibilidad (el impacto ambiental, social y económico) y el cumplimento de la ley de cada país ya que todas las normas de certificación están basadas en las normativas y en las leyes vigentes de cada país."

A través de los años se han formado varios sellos en el mundo que apoyan esta causa y las tendencias hacia esta forma de trabajo es más grande cada día.

\section{Los sellos bajo los cuales ATLANTIC exporta son:}

1. Café orgánico certificado. Es un sistema de producción que tiene como fundamento la conservación y mejoramiento de la fertilidad del suelo, con técnicas e insumos compatibles con el medio ambiente y la conservación de la biodiversidad vegetal y animal. El café orgánico es el primer sello en el ámbito sostenible y la única norma que se ha incorporado a la legislación de muchos países.

2. El café (FLO) certificado (Fairtrade Labelling Organizations). Fairtrade es un sistema de certificación para productos que cumplen con los estándares medioambientales, laborales y de desarrollo establecidos por FLO International. El objetivo de la certificación Fairtrade es "promocionar la certificación de productos de comercio justo y su consumo y contribuir así a ampliar el impacto de este comercio alternativo".

Perú es el mayor exportador de café Fairtrade, seguido por Colombia, México y Nicaragua.

1. Utz Certified. La certificación Utz Certified es la más reciente de las certificaciones importantes. Desde que se pusiera en marcha en 2003, Utz ha registrado un fuerte crecimiento, sobre todo en el mercado europeo. Se centra en la promoción de buenas prácticas empresariales como componente importante para lograr la sostenibilidad. Su norma incorpora plenamente la norma GLOBALG.A.P para el café y recoge una serie de criterios sociales y medioambientales para la adopción de prácticas responsables en el cultivo de café y la gestión eficiente de las explotaciones.

2. Starbucks Coffee Company. Starbucks es una compañía y el sello de certificación es Café Practices, Starbucks es la mayor red de cafeterías del mundo, promueve el cultivo y beneficiado de forma sostenible y su negocio en Nicaragua es con las exportadoras.

3. Rainforest Alliance. Las normas de Rainforest Alliance se basan en una lucha integrada contra las plagas y contemplan el uso de algunos productos agroquímicos. Estas normas promueven la biodiversidad, pero también velan por la protección del bienestar de los trabajadores. 
4. Nespresso AAA. Nicaragua es el país más reciente para entrar en el programa d café sostenible Nespresso AAA. Es la certificación que pide más requisitos y según el responsable de certificaciones de Jinotega es el sello más difícil de conseguir después de Rainforest Alliance, actualmente ATLANTIC tiene 45 fincas certificadas bajo este sello.

5. Código Común para la Comunidad Cafetalera (4C). Constituye la norma más básica, el proceso de la Asociación 4C puede resultar más accesible para los grandes productores o grupos de productores (20 toneladas como mínimo) que no estén dispuestos a cumplir los requisitos más exigentes de otras normas de certificación, o no puedan hacerlo. Ofrece un procedimiento de verificación que no es tan riguroso ni conlleva los gastos de un proceso de certificación.

\section{Requisitos para la certificación}

"Para incluir a un productor en el proceso de certificación éste debe ser un cliente activo de la empresa, que tenga crédito a mediano o largo plazo, que sea un cliente " $A$ " es decir, un cliente que cumple a la hora de pagar el crédito y que nos entregue toda la cosecha, también se toma en cuenta el volumen y la calidad del café". (Ing. Gisselle Waleska Espinal, asesor técnico de sostenibilidad-Jinotega).

Generalmente los requisitos que debe cumplir una finca para estar en un programa sostenible están ligados a tres ejes fundamentales basados en las leyes nacionales: Ambiental, Social y Económico. El coordinador de sostenibilidad explica:

"Parte de la responsabilidad social a nivel de empresa es otorgar becas a hijos de los productores de café, pero la responsabilidad social en sí, es realmente lo que nosotros hacemos: vamos hasta las fincas y damos asesorías, instamos a que en las fincas se pague el salario mínimo, que las condiciones de trabajo sean justas, que no hayan niños trabajando, etc.

La responsabilidad ambiental se refiere a las buenas prácticas agrícolas, que cuidemos los recursos naturales, que no se contamine, etc.

Para el cumplimiento de estos requisitos la exportadora se basa en un SGSA "Sistema de Gestión Social Ambiental", el cual es un sistema que contiene principios, programas, procedimientos y registros que los productores deben aplicar en las fincas."

ATLANTIC trabaja con la norma de Rainforest Alliance que tiene diez principios: 1) Sistema de gestión social ambiental; 2) Conservación de ecosistemas; 3) Protección de la vida silvestre; 4) Conservación de los recursos hídricos; 5) Trato justo y buenas condiciones para los trabajadores; 6) Salud y seguridad ocupacional; 7) Relaciones con la comunidad; 8) Manejo integrado del cultivo; 9) Manejo y conservación del suelo; 10) Manejo integrado de desechos.

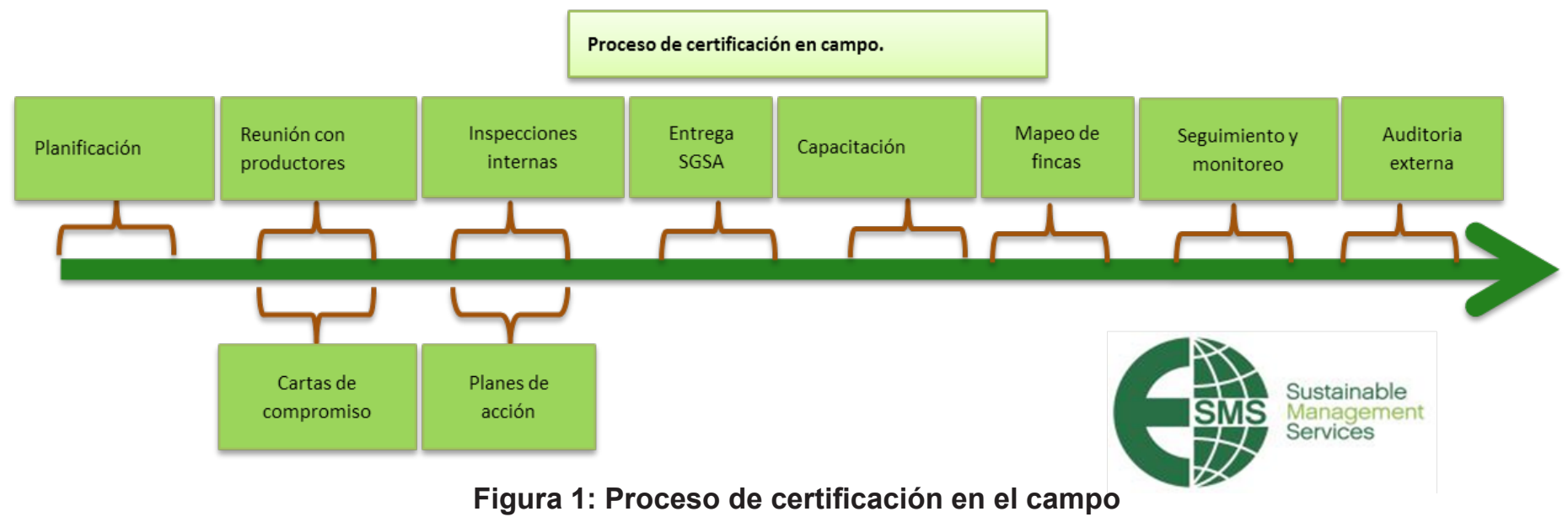


Cuando las empresas tostadoras de café solicitan cierta cantidad de café certificado a exportadora ATLANTIC, esta debe buscar la manera de responder a esa demanda, por lo tanto debe buscar productores que estén dispuestos a integrarse a un proceso de certificación.

En el proceso de certificación de fincas lo que se hace es reunir a varios productores de una zona de interés para ver quienes quieren participar, se reúne un máximo de cien productores de los cuales quizá solamente cinco de ellos acepten certificar su finca.

La empresa hace una reunión con los productores que han aceptado la propuesta y firman una carta de compromiso y a partir de ahí comienza el proceso. El responsable de certificación y su equipo técnico se reúnen en las fincas con los productores para hacer inspecciones internas, dentro de estas inspecciones sale todo lo malo que hay en la finca y de acuerdo a esto se genera un plan de acción, para entonces poder corregir. El Ingeniero Lanzas menciona:

"Los problemas que hay cuando estamos en la evaluación es que hay que hacer modificaciones de infraestructura, o correcciones en los pagos de salario, esos son puntos muy delicados y a veces ellos se rehúsan a cumplir estas obligaciones."

El equipo técnico capacita a los dueños de fincas, a los administradores de fincas y también a los trabajadores que son los que hacen el trabajo operativo; además hacen actividades como mapeo de fincas, análisis de suelo, análisis de agua, monitoreo constante (para evaluar el nivel de cumplimiento del plan de acción establecido), intercambio entre fincas, entre otras cosas que son necesarias para que el proceso de certificación se lleve a cabo con éxito.

Luego viene la auditoría externa que es realizada por una tercera parte, por ejemplo una empresa que hace auditorías externas es Mayacert, ésta es una empresa que tiene oficinas en Guatemala, Costa
Rica, Honduras y en Nicaragua, ellos son entes que tienen la acreditación global y la potestad de hacer las evaluaciones pertinentes. Si las fincas cumplen todos los requisitos se les da un sello, de lo contrario el sello no es aprobado, es decir ese café no se puede vender, por consiguiente la empresa tiene un problema porque no puede entregarle el café al tostador y éste no satisface la demanda del consumidor.

ATLANTIC tiene algunas limitantes para poder acceder al mercado diferenciado, según el responsable de certificaciones, la empresa tiene que estar buscando mercados, otro inconveniente para la empresa es que tiene que estar luchando bastante con el nivel cultural de los productores, con su filosofía convencional ya que ellos no están familiarizados o concientizados con el proceso de responsabilidad social. La Ing. Gisselle Waleska Espinal comenta:

"Otra limitante es el dinero. Para que podamos entrar al proceso de certificación de una finca tenemos que cumplir con varios criterios y algunos son críticos que si no los cumplimos no pasamos a certificar, a veces esos criterios los productores no los tienen y en algunos casos tienen que incurrir en gastos. Los gastos dependen del tamaño de la finca y de las condiciones en las que ésta se encuentre. La empresa brinda crédito a los productores pero no están destinados a la certificación sino para el mantenimiento del café.

El financiamiento para el mantenimiento de los cafetales se basa en un avaluó, existe un comité de crédito que es quien decide a quién se le puede dar crédito y que cantidad se puede desembolsar. El problema que tenemos ahorita es que la cosecha de esta temporada será baja y algunos clientes se nos han pasado a la competencia (CISA Exportadora) porque ellos no entienden que no se les puede dar más y en realidad la otra empresa tampoco les va a desembolsar lo que ellos quieren..."

\section{Calidad en el proceso de producción del café}

La calidad del café depende de la variedad que se 
siembra y de la altura de los cafetales. Para alturas igual o menos a $950 \mathrm{msnm}$, es recomendable sembrar variedades resistentes a la roya, las más comunes son Catimor y Sarchimor; para alturas superiores a $950 \mathrm{msnm}$ se recomienda variedades resistentes a ojo de gallo y para calidad de taza variedades como Catuaí, Caturra e Híbridos.

Se pueden ver ciertas etapas de cuidado para conservar la calidad durante el proceso productivo del café:

1. Lo ideal es cortar solo el café completamente maduro, sin embargo las condiciones de clima lluvioso pueden exigir el corte de café pinto para evitar caída de frutos que mermen la cosecha.

2. La sobre maduración de café produce problemas de calidad y para minimizar su ocurrencia el intervalo de tiempo entre pasadas de corte en cada plantío debe ser de 15 a 20 días promedio.

3. Se debe evitar el corte de café verde y para ello es necesario instruir constantemente a los cortadores y la buena supervisión.

4. El traslado del café al beneficio húmedo debe ser inmediatamente después de la medida en el campo para evitar deterioro o inicio de la fermentación del fruto.

5. El buen beneficiado húmedo inicia con un equipo de despulpado limpio y bien calibrado para evitar contaminación que dañe la calidad y daños por mordedura o quebradura de granos.

6. El despulpado debe ser en seco, esto permite mejor eficiencia de la despulpadora y reduce la cantidad de aguas servidas que haya que tratar para evitar contaminación del medio ambiente.

7. El fermentado debe ser el óptimo, esta actividad se realiza para quitar el mucílago o miel que posee el grano maduro, le tiempo de fermentación está en dependencia de zonas por condiciones climáticas, infraestructuras y volumen de café a fermentar, una forma práctica de determinar si está listo es la prueba de introducir un palo redondo y grueso en el café hasta el fondo de la pila y si al sacarlo queda un hueco, es indicador que está de punto. El exceso de fermentación causa problemas de taza, en el pergamino se percibe olor a vinagre o chicha fermentada y toma color rojizo, observándose más claramente en la ranura del grano.

8. El lavado del café para quitar el mucilago debe realizarse con agua limpia, sin agentes contaminantes, ya que esto puede ocasionar pérdida de calidad nata del grano.

9. Es buena práctica orear el café en cajillas de madera y cedazo para reducir los riesgos de fermentación adicional o presencia de moho si el productor lo almacena por un corto tiempo antes de llevarlo al centro de acopio.

10. El transporte del café lavado debe ocurrir a lo inmediato de la lavada, así este llegara al beneficio seco donde se secara para luego almacenarse, si este café tarda mucho tiempo en el transporte puede ocurrir fermentación, proceso que causa daños en la calidad.

El Ing. Thomas Espinoza, catador del beneficio seco en Condega explica:

"El café que entra al beneficio viene propiamente del cliente o el cliente llega a una agencia en las localidades de la empresa ubicadas en municipios cercanos para que ellos entreguen su café e inmediatamente el agente lo traslada. Aquí en el beneficio solo se puede mantener la calidad o se puede echar a perder, la calidad depende del grado de humedad, la humedad provoca hongo y también depende del almacenamiento del café, si el productor deja almacenado mucho tiempo el café es muy fácil que éste pierda calidad". 


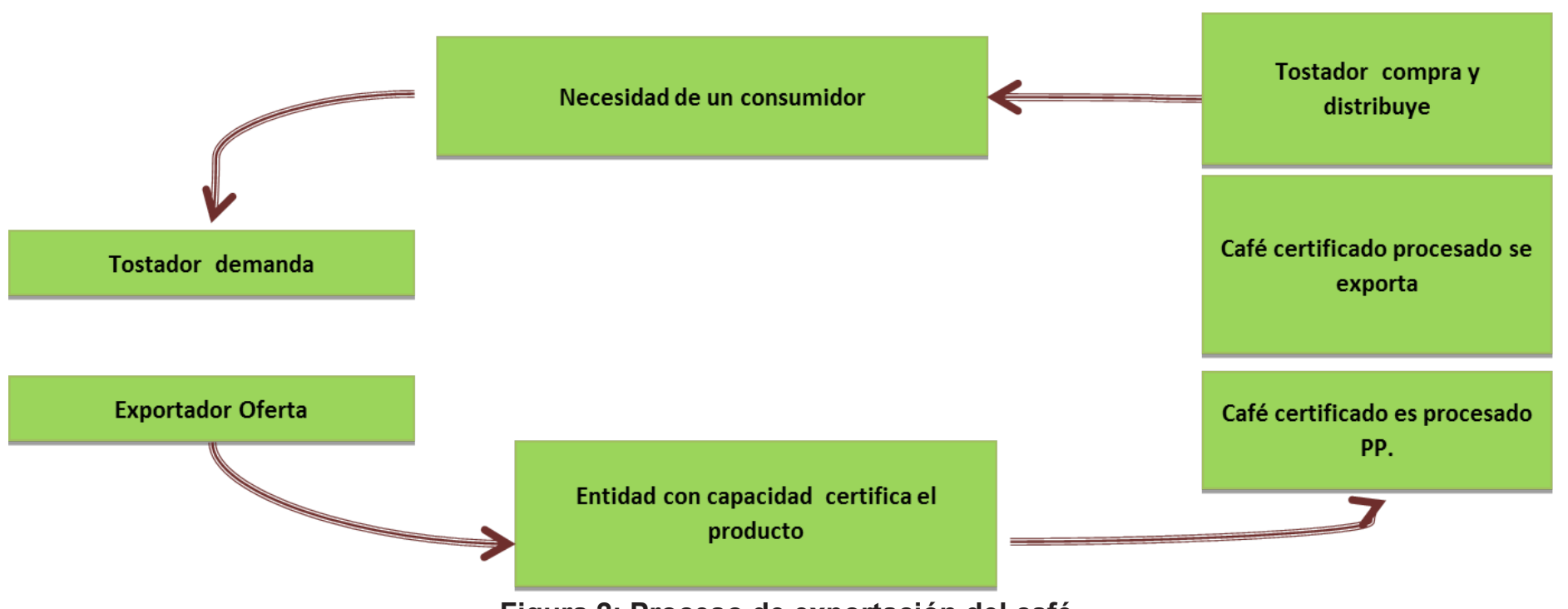

Figura 2: Proceso de exportación del café

El café certificado nace como una necesidad de los consumidores. En el mercado europeo es donde existe la mayor demanda de café certificado.

El tostador es quien distribuye el café a los consumidores como producto terminado, cuando tiene una demanda se avoca directamente con el exportador, en este caso es ATLANTIC.

\section{Exportadora ATLANTIC cuenta con un área de Servicio} de Manejo Sostenible, esta oficina está ubicada en Jinotega y está integrada por equipos técnicos o colaboradores que van a las fincas y logran que el café sea certificado.

Cuando el café se certifica se maneja de una forma diferenciada en los beneficios secos o plantas procesadoras, no puede estar mesclado con el café convencional, por un asunto de trazabilidad.

El proceso de beneficiado seco del café consta de cuatro etapas principales:

1. Recepción. Se clasifica el café en pergamino o en oro, a través de la observación visual, olfáltil y táctil, determinando por la calidad de las observaciones realizadas, los defectos que el lote contiene y la humedad por medio de una muestra de $175 \mathrm{grs}$ en el caso de café en pergamino y 250 grs en caso de café oro extraída de cada uno de los sacos que conforman un lote determinado, es introducida en un probador de humedad llamado TESTER.

Se emite un recibo de recepción, rellenando los espacios vacíos con los datos brindados por la remisión con la que fue enviado el café al beneficio seco más los datos de los resultados obtenidos por el análisis del recibidor en la clasificación de lote. Se elabora un ticket para identificar el lote del café indicando: procedencia, productor, cantidad de sacos, quintales netos, calidad, fecha y \# de recibo de recepción. Este ticket es colocado en uno de los sacos de lote.

2. Secado. Los lotes en pergamino recibidos e identificados debidamente por la recepción son trasladados en tráiler a los diferentes patios para ser secados, estos lotes son recibidos por el jefe de patio quien se encarga de darles el manejo diario observando puntos de humedad hasta lograr obtener el grado necesario para ser trillado, este proceso de secado en patio se da a través del rastrillado continuo por personas destinadas a realizar dicha labor más el calor de la luz solar que recibe, esta etapa puede ser por un periodo de 5 a 7 días dependiendo del grado de humedad con el que se recibió. 
En caso de que el clima no sea favorable para este tipo de secado se utilizan maquinas secadoras, primero es pre-secado en patios hasta alcanzar el grado de humedad que oscila entre los 22 a 26 grados de temperatura, es trasladado a las tolvas las cuales alimentan a cada una de las secadoras, estas reciben un calor continuo de 45 a 50 grados máximo de temperatura caliente. Cada secadora tiene la capacidad de 70, 90, 100 quintales dependiendo de su tamaño. Seguidamente se descargan y es trasladado a las tolvas de empaque (sacos macen) se enfarda y se pesa, es estivado esperando el análisis de catación para después ser trasladado a las estivas finales en espera de ser trillado.

Tanto para el secado en patios como para el secado en máquinas el café debe de ser reposado mínimo 15 días después de alcanzar el grado de humedad deseado antes de ser trillado. Se elabora un recibo de Entrada de Café en Pergamino a Bodega.

3. Trillado y clasificado. Primero se determina la cantidad y calidad necesaria para los embarques programados, se emite una orden de trillo. Se inicia el proceso de trillado pasando primero el pergamino por una maquina pre-limpiadora, seguidamente es transportado por un elevador hacia las tolvas que alimentan al trillo, se procesan un equivalente de 90 quintales oro por 1 hora. Este café oro es sometido a un proceso continuo por un pre-limpiador de café oro, remitiendo el café a 4 catadores los que a la vez descargan sobre 2 clasificadoras de tamaño donde se separan las cribas grandes y el resto de café pasa directo a las maquinas vibradoras que seleccionan el grano por peso, las primeras bocas salen limpias, las segundas bocas pasan por un proceso en las máquinas electrónicas. Estos resultados finales nos determinan los rendimientos obtenidos en todo el proceso de trillado. Se elabora un documento Entrada de Café oro a Bodega indicando los resultados finales. El producto final es empacado en sacos macen.

4. Mezcla, embarque y almacenamiento. En base a instrucciones de embarque programadas, se ordena la marcada de los sacos de exportación, después el laboratorio de catación se encarga de realizar los análisis de los lotes que van a formar un embarque especifico, una vez realizada esta labor se emite una orden de mezcla y es entregada a la persona encargada de dirigir las bochadas, los lotes seleccionados para la preparación del embarque son trasladados al sector en donde se encuentra un aparato llamado Bochador el cual descarga el café ya mezclado en una tolva y finalmente el producto final es empacado en los sacos de exportación y pesado en una pesa electrónica que está programada para realizar diferentes pesos según el tipo de saco que se va a utilizar (sacos de 150, 151 y 152 libras) el saco es costurado para después ser estivado en maquetas de 250, 275 a 300 sacos según las cantidades en sacos que llevara cada contenedor. Al momento del despachado del café esta salida es soportada por la emisión de una Remisión de café oro. Cuando el café es procesado se cumple el contrato que hizo el exportador (ATLANTIC) con el tostador quien lo compra, lo procesa y lo distribuye.

\section{Clientes tostadores de exportadora ATLANTIC, S.A}

Los tostadores que importan el café certificado de ATLANTIC están ubicados en California, Nueva York, Miami, Australia, Orrville Ohio, entre otros países. Los principales son: 1) The floger coffee. Co; 2) Atlantic USA, Inc.; 3) Atlantic Speciallity coffee; 4) Starbucks; 5) Nespresso; 6) Ecom Japon; 7) HA. Bennett \& Sons Pty. Ltd; 8) Coex Coffee International, Inc.; 9) Campbell. Bewley group. 


\section{Exportaciones de exportadora ATLANTIC por sellos de certificación}

Del 1 de octubre del 2012 hasta el 30 de septiembre del 2013 ATLANTIC exportó en total 666,149.54 quintales de café, según la Licenciada Ann Traumann el café certificado representa el $30 \%$ del total de las exportaciones y el $70 \%$ del café exportado es convencional.

La gráfica muestra el porcentaje de las exportaciones de ATLANTIC por sellos de certificación. En el ciclo 2012-2013 las exportaciones de café certificado disminuyeron en un $28 \%$ en comparación con el ciclo anterior, por tal razón ATLANTIC tuvo que buscar nuevos mercados y un $3 \%$ de las exportaciones de café fueron comercializadas bajo el sello $4 \mathrm{C}$ que es la certificación que exige menos requisitos y menor calidad en comparación a los demás sellos con los que está trabajando actualmente la exportadora.

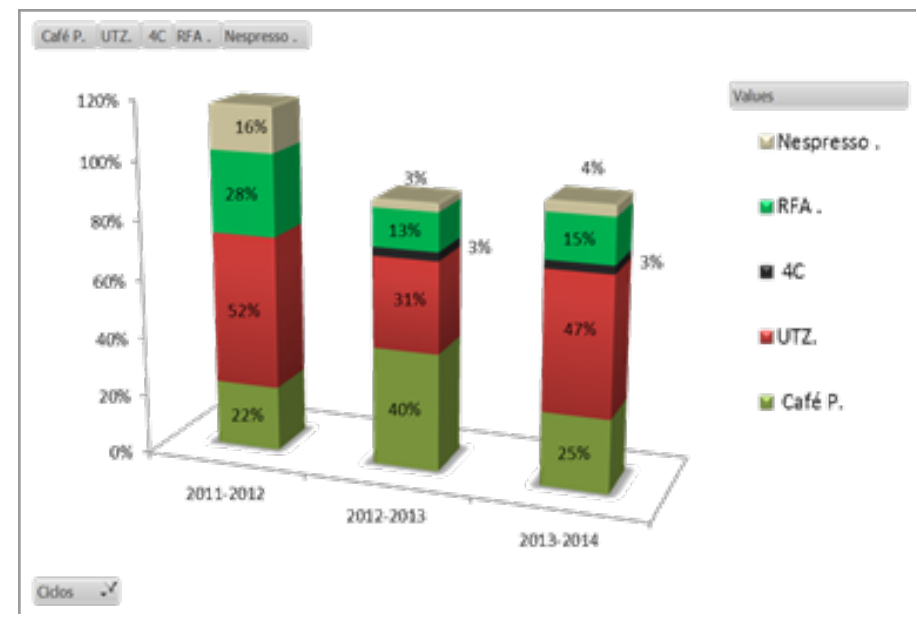

La mayor afectación fue ocasionada por las condiciones climáticas y la enfermedad conocida como roya del café que incidió negativamente en la calidad de este producto. Para el ciclo actual la empresa pretende aumentar en un 5\% dichas exportaciones en comparación al ciclo 2012-2013.

\section{Precios de exportación}

En el ciclo 2011-2012 los precios del café exportado por ATLANTIC oscilaron entre los $\$ 160$ y $\$ 180$ (ciento sesenta y ciento ochenta dólares) el quintal oro, mientras que en el ciclo 2012-2013 los precios se mantuvieron entre los $\$ 120$ y $\$ 140$ (ciento veinte y ciento cuarenta dólares). Los precios disminuyen porque existen competidores internacionales como Vietnam, Brasil y Colombia que producen grandes cantidades de café saturando los mercados.

La variedad que comúnmente se cultiva en Nicaragua es arábica, por lo tanto para la fijación del precio del café se utiliza como marco de referencia el precio que rige la bolsa de Nueva York en el momento de la negociación. Este precio es la base para determinar el precio final, que puede verse aumentado o disminuido en función de la calidad del café que se está negociando, el aumento o disminución del precio es llamado diferencial.

En la siguiente tabla se muestran los diferenciales por sellos de certificación obtenidos por Exportadora ATLANTIC, S.A en el año actual:

\begin{tabular}{|l|l|}
\hline Sellos de certificación & Diferencial U\$/qq \\
\hline Nespresso AAA & +15 \\
\hline Utz Certified & +5 \\
\hline $\begin{array}{l}\text { Starbucks/ Café } \\
\text { Practices }\end{array}$ & +10 \\
\hline Rainforest Alliance & +22 \\
\hline 4C & +2 \\
\hline
\end{tabular}

El ingeniero Jairo Rodríguez, Gerente Regional explicó:

"Al productor no se le paga ese diferencial, porque no se garantiza que todo el café que entrega se va a exportar bajo cierto sello de certificación, lo que se hace es comprarlo al precio de la bolsa de Nueva York, y al final de la cosecha se les hace entrega de un bono o incentivo dependiendo de la cantidad $y$ calidad del café que entregó."

Todo el café se abona en dólares. Por lo general los términos de pago son a la llegada del café, o contra 
documento. En este último caso el pago se efectúa antes de la llegada, ya que los documentos llegan en avión, mientras que el café lo hace en barco.

\section{Requisitos para la exportación}

Cuando ATLANTIC tiene una solicitud de cierta cantidad de café por parte del cliente, ésta elabora un plan de acuerdo a la venta que se va a hacer, en este caso el plan es realizado por el departamento de comercialización y es enviado al beneficio seco con un mes de antelación.

El beneficio puede objetar o aceptar la propuesta de fechas de embarque. Cuando el plan ya está confirmado, se sube a un sistema que tiene Exportadora ATLANTIC Ilamado Módulo de Trafico, ahí tienen que ir todos los contratos especificando la calidad, cantidad, los números de defectos que debe llevar ese café, el destino, etc.

Una vez que ya están todos los contratos en el módulo de tráfico se le solicita al beneficio las muestras de café que tienen que ser enviadas al cliente para su análisis y aprobación, en dado caso que el cliente rechace la muestra éste manda de retorno los comentarios acerca del análisis que realizó, dependiendo de los comentarios que ellos brinden el beneficio realiza una nueva muestra y es enviada nuevamente al cliente para su previa aprobación. La licenciada Vanessa Lam, coordinadora del departamento de tráfico menciona:

"Nosotros tenemos como regla que cada $20 \mathrm{del}$ mes anterior al mes de embarque debemos hacer todas las instrucciones que el cliente nos pide, por ejemplo si el cliente pide que el contenedor este empapelado, que las argollas estén bien colocadas, etc. realizamos también la solicitud del Booking que es la solicitud que se hace a la Naviera para que el contenedor arribe hacia cierto beneficio en una fecha acordada con el beneficio. Se realiza la instrucción de embarque porque el cliente a veces especifica ciertas características que debe llevar el marcado de los sacos, por ejemplo cada saco va marcado con el nombre de Exportadora ATLANTIC, la calidad, la certificación, producto de Nicaragua, cosecha 20122013. Hay ventas que son estándares y otras que son para clientes súper especiales."

El beneficio trabaja en base a la instrucción de embarque donde se detalla la cantidad de sacos, el tipo de saco, peso bruto, la tara (peso bruto del saco vacío), el peso neto, la cantidad de quintales, precios, embarque de salida y de llegada, cuál será la naviera, el tipo de empaque, etc. Para que el beneficio pueda trabajar toda la información tiene que ser correcta.

\section{Fase}

1. Factura proforma. La primera fase comienza cuando la empresa realiza la solicitud de un precio estándar al área de finanzas para poder elaborar la factura proforma. El área de finanzas informa al departamento de tráfico cual es el precio del café para determinado contrato y con ese precio se factura. La factura se acompaña con la instrucción de embarque y se pasa a beneficio seco en Sebaco o Condega.

2. Instrucción de embarque. Las instrucciones de embarque pueden amparar uno o más contenedores, lo máximo que se permite embarcar o reflejarse en un Bill of Lading son 10 contenedores. La Lic. Vanessa Gutiérrez explicó: "Usualmente nuestro tope son diez contenedores en una instrucción de embarque, a no ser que por la complejidad del proceso consensuemos y digamos: no, en beneficio no van a estar esos 10 contenedores porque paralelo tenemos que analizar el tiempo de demoraje de cada contenedor. Las navieras cobran no exactamente por el contenedor estando el predio, las navieras nos dan de uno a 3 días para cargar, despachar y colocaren puerto, después de ese tiempo empiezan 
a cobrar demoraje por el cabezal y el chasis. Dependiendo de los términos de la exportación se usan navieras contratadas directamente por ATLANTIC o navieras que solicita el cliente."

La Naviera es a quien se le paga el servicio por el traslado del café en los contenedores, tanto terrestre como marítimo, es decir, del beneficio al puerto y del barco al cliente.

3. Certificado de calidad (CONACAFE). Luego se manda a certificar el café a una entidad que está ligada al gobierno llamada CONACAFE, lo que hace esta institución es prácticamente una certificación de calidad. La licenciada Vanessa Gutiérrez explicó:

"Esto lo hacemos a través de laboratorios certificados por el Organismo Nacional de Certificación de la Calidad del Café ONCC, estos laboratorios vana CONACAFE y gestionan esa certificación."

Para la certificación en CONACAFE se debe tener el precio, la factura, calidad, puerto de embarque, puerto de llegada, la cantidad en sacos de $69 \mathrm{~kg}$, porque a CONACAFE se le detalla como saco de $69 \mathrm{~kg}$, si el café va en empaques de mayor o menor peso, el departamento tráfico debe sacar la equivalencia. Cuando se obtiene la certificación de CONACAFE, se tienen dos cosas: El certificado físico y el número de lote o ICO, el cual es registrado en CETREX. El número ICO está conformado por tres digitaciones separadas por un guion, ejemplo: $017-\mathrm{XXX}$ - XXXX. Cada exportación tiene un número de lote agregado. Cuando ATLANTIC exporta a un cliente, tiene un número de lote para esa exportación y en las próximas ventas el número de lote es diferente. Cada país tiene un código ICO diferente en el caso de Nicaragua el ICO estándar del café es 017. La primera cifra corresponde al país (Nicaragua); la segunda es del embarcador, el último dígito es la referencia o el número de lote que ATLANTIC está exportando al cliente. El segundo dígito cambia dependiendo del embarcador y el último es una referencia interna propia de la empresa. La licenciada Vanessa Gutiérrez Menciona:

"El número de lote o ICO es más que todo por el tema de trazabilidad, si hay un problema con este café a lo largo del destino entonces se nos hace más fácil identificar cual es el lote y las causas por las cuales llego ese café no apto según las especificaciones del cliente."

4. Declaración de mercancía. Cuando el lote o ICO está digitado en CETREX el departamento de tráfico elabora un FUE (Formato Único de Exportación). Existen dos tipos de formatos de exportación: uno para las áreas centroamericanas denominada FAUCA(Formulario Aduanero Único Centroamericano) y otra para exportaciones fuera del CA4 la cual está conformada por 4 regiones centroamericanas que son Guatemala, Honduras, El Salvador y Nicaragua. A excepción de esos países se utiliza FUE. La Lic. Vanessa Gutiérrez menciona:

"Generalmente todas nuestras exportaciones son fuera de Centroamérica, como Estados Unidos, Europa y el resto del mundo. No exportamos a Centroamérica porque varios países Centroamericanos también son exportadores de café."

EI FUE es una declaración de mercancía donde se muestra el cliente al que la empresa va a exportar, la dirección, el país de destino, los puertos o las aduanas fronterizas por donde va a salir el café, el número de la factura, cantidad en quintales y en kilogramos que se va a exportar, el valor FOB de la mercadería, el número de lote o ICO, la calidad genérica del café, etc. este documento también 
contiene una casilla de las observaciones donde se describe cómo se va a embalar el café. La Lic. Gutiérrez Explica:

"Existen varios tipos de embalaje: en sacos, que pueden ser de $69 \mathrm{~kg}$ que es lo que usualmente solicita CETREX para poder llevar una estadística de las exportaciones que se realizan; el otro es en sacos jumbo que le llamamos a granel, es un gran saco que pesa aproximadamente 1.5libras; están los sacos bigbag que ampararan una tonelada métrica y están otros que pueden ir en cajas pero como un café empacado al vacío denominado vacuum pack que pueden ser de 30 a $35 \mathrm{~kg}$. Cuando la solicitud va en embalajes de caja el peso en kilogramo lo determina el cliente dependiendo de la negociación que hagamos con él."

5. Certificación Fitosanitaria emitida por el MAGFOR. Este documento es el Fito o certificación sanitaria el cual se obtiene enviando una muestra de café al MAGFOR. La certificación debe tener el sello de MAGFOR y el de CETREX.

Una vez que toda esa documentación está lista se le tiene que enviar al agente aduanero para que él realice el trámite ante aduana, ya sea en aduana fronteriza o en los diferentes puertos. La licenciada Vanessa Gutiérrez menciona:

"Nosotros estamos utilizando prácticamente dos puertos (Puerto Corinto, de donde sal el 60\% de las exportaciones y Puerto Limón en Costa Rica, de donde sale aproximadamente el $40 \%$ de éstas). Cuando la agencia aduanera ha realizado ese trámite la documentación retorna a nosotros."

\section{Fase}

La segunda vuelta o fase se realiza hasta que la exportadora tiene todos los documentos sellados por la aduana. Para hacer la segunda vuelta el embarque ya tiene que haber zarpado. Todos los documentos que se envían a los clientes deben ir con fecha de onbor es decir, la fecha de zarpe del barco o booking.

1. Tramites con la Línea Naviera Bill of Lading. El Bill of Lading significa cocimiento de embarque. Es el documento que emite la línea naviera que está trasladando los contenedores. Este documento contiene información sobre quién es el exportador, quien es el importador, el puerto en el que se cargó, lo que lleva el contenedor, el peso, etc., es decir toda la información entre la exportadora y el cliente. El documento va firmado y sellado por la naviera.

"Este documento es importante porque la persona que tiene el original es el propietario del café (si Exportadora ATLANTIC tiene este documento el café es de nuestra propiedad, pero si ya lo pasamos al cliente, el café es propiedad suya).

El Bill of Lading contiene en su parte reversa ciertas cláusulas que mencionan las navieras. Por ejemplo ¿qué pasa cuando el café va en un barco y por cosas del destino los contenedores caen al mar? Para eso en el BL salen todas las cláusulas de cómo se debe proceder y hasta dónde está el alcance de la responsabilidad de la naviera."

\section{Certificado de Origen OIC y SGP - Factura}

Final. Para la segunda vuelta se utiliza la factura final. Existen dos tipos de envío de documentación a CETREX: una para aquellas cargas cuyo destino es Estados Unidos y la otra para el resto de los países fuera del CA4. Si se trata de una exportación a Estados Unidos tiene que llevar dos copias de la factura original, dos copias del BL con la fecha de onbor (tienen que ir tres juegos: el original, una copia del importador y una COPIA de CETREX), también se envía el certificado de calidad que emite CONACAFÉ y la copia del contrato local. 
Cuando se le envía la documentación a CETREX éste le regresa dos documentos a la exportadora: El OIC Y SGP. Cuando es carga de Estados Unidos la exportadora solo recibe el OIC que es prácticamente un tratado de libre comercio, este documento sirve para exonerar o reducir el DAI (Declaración Arancelaria de la Importación). Con el OIC el cliente bien deja de pagar el impuesto como tal o se reduce el porcentaje de impuestos a pagar, al cliente le interesa mucho tener ese documento porque si no se le hace más caro importar el café.

El cliente o tostador requiere la factura final original con los elementos de cómo ellos deben de pagar. En la factura va el número de IVA, número de venta, la cantidad de café, el tipo de café, tipo de empaque, fecha de exportación, el término de venta, el precio, la forma de pago y el número de Bill of Lading, adicional requiere el ICO y el SGP original con el sello de CETREX, el Bill of Lading original, dos juegos de la certificación fitosanitaria realizada por MAGFOR (original y copia) y el certificado original de CONACAFE. La licenciada Vanessa Gutiérrez menciona:

"Eso es para un embarque estándar porque hay cierta documentación de clientes especiales que por su legislación requieren otro tipo de documento, por ejemplo si el café va a ir fumigado si el café necesita un certificado de origen por parte de la cámara de comercio, etc. entonces el cliente tiene que solicitarnos esa documentación, eso estará en dependencia del destino, del cliente y del tipo de sello bajo el cual se está exportando".

\section{Análisis FODA}

A partir del análisis de los resultados de la presente investigación se identificaron las principales fortalezas, oportunidades, debilidades y amenazas de Exportadora ATLANTIC, S.A. A través de este análisis se proponen estrategias para mejorar los procesos de certificación de la calidad y exportación de café certificado de dicha empresa.
Fortalezas: 1) Es una empresa sólida y una de las principales exportadoras de café en Nicaragua; 2) Personal capacitado en las diferentes áreas de la empresa; 3) Tecnología avanzada en los beneficios secos; 4) Estricto control de calidad; 5) Asistencia técnica a los productores; 6) Tiene centros de compra en los principales departamentos productores de café (Jinotega, Matagalpa y Ocotal); 7) Miembro del grupo ECOM con compradores en Estados Unidos y Europa.

Oportunidades: 1) Crecimiento continuo en la demanda de café certificado en Estados Unidos y Europa; 2) Precio diferenciado para el café certificado; 3)El clima del país permite que se coseche una mejor calidad de café en comparación a países desarrollados (Brasil Y Vietnam).

Debilidades: 1) Falta de disposición de los productores para ingresar al proceso de certificación; 2) Poco tiempo exportando café certificado; 3) Difícil acceso al mercado diferenciado; 4) Las exportaciones de café certificado representan tan solo el $30 \%$ del total de las exportaciones; 5) No existe un plan de financiamiento para que los productores certifiquen sus fincas; 6) Disminución en el financiamiento para mantenimiento de cafetales.

Amenazas: 1) Disminución en la calidad y productividad del cultivo por las condiciones climáticas; 2) Ingreso de nuevos ofertantes de café certificado al mercado internacional; 3) Caída del precio del café en el mercado internacional; 4) La roya ha afectado en un $32 \%$ a los cafetales, disminuyendo la capacidad de oferta de la exportadora. 
ESTRATEGIAS PARA MEJORAR EL PROCESO DE CERTIFICACIÓN DE CALIDAD DEL CAFÉ PARA LAS EXPORTACIONES DE EXPORTADORA ATLANTIC, S.A.

Línea $\mathrm{N}^{\circ}$ 1: Motivación a los productores de café de certificación. Objetivo General: Promover el acercamiento del productor al concepto de producción sostenible para acceder al mercado diferenciado.

Línea N²: Penetración a nuevos mercados. Objetivo General: Ofertar el café certificado en los mercados internacionales proyectando una imagen de diferenciación.

Línea $\mathrm{N}^{\circ}$ 3: Incremento en el volumen de exportación de café certificado. Objetivo General: Incrementar la cantidad de fincas certificadas para abastecer eficientemente la demanda de los clientes tostadores.

Línea $\mathrm{N}^{\circ}$ 4: Creación de una línea de crédito para la certificación de fincas. Objetivo General: Otorgar financiamiento para certificación de fincas a los productores que aún no son miembros de la cadena de exportación de café al mercado diferenciado.

Línea $N^{\circ}$ : Aumento en el financiamiento a productores para el mantenimiento de los cafetales. Objetivo General: Otorgar el financiamiento necesario para el mantenimiento de cafetales a fin de asegurar la calidad y la cantidad del café acopiado por Exportadora ATLANTIC, S.A.

\section{CONCLUSIONES}

Exportadora ATLANTIC, S.A presenta muchas ventajas competitivas que puede explotar para competir a nivel nacional e internacional. El mercado de café diferenciado está en constante crecimiento, sin embargo es necesario que haya participación de los productores para exportar café de especialidad.

Para que el café ingrese al mercado diferenciado, es necesario que cuente con una certificación que lo acredite, para aplicar a ella el productor debe cumplir con estrictas normas de producción, el equipo técnico de ATLANTIC se encarga de capacitar a los productores y la aprobación de la certificación es realizada por una empresa externa.

Generalmente los requisitos que debe cumplir una finca para estar en un programa sostenible están ligados a tres ejes fundamentales (ambiental, social y económico).La exportadora tiene algunos problemas para certificar las fincas ya que algunos requisitos para la certificación implican rediseño de infraestructura, corrección en los salarios entre otros aspectos que requieren inversión por parte de los productores y no existe un plan de financiamiento para la certificación de fincas.

La calidad del café depende de la variedad que se siembra, de la altura de los cafetales, del grado de humedad, del adecuado almacenamiento del café y de las buenas practicas realizadas durante la recolección, despulpe, fermentación, lavado y secado del grano.

Hasta el 31 de julio del 2013 ATLANTIC exportó $581,603.35$ quintales de café, las exportaciones de café certificado representan el $30 \%$ del total de las exportaciones. Actualmente el precio del café según la bolsa de Nueva York es de $\$ 120$ el quintal. Los precios en mercado del café se ven afectados por un exceso de oferta, causado por la sobreproducción mundial.

\section{BIBLIOGRAFÍA}

Navas, Azucena. (2008). Curso básico de derecho mercantil. Universitaria. UNAN León, página 30.

Ferrell. O. C, y Hartline, M. D. (2006). Estrategia de Marketing Tercera edición. [En línea]. Consultado: 
[20, Abril, 2013]. Disponible en: http: books.google. com.ni/book?isbn=970686496

Asociación Nacional del Café. El Beneficio Húmedo. [En línea].Consultado [9, Agosto, 2013]. Disponible en: http://www.anacafe. org/glifos/index.php?title=Caficultura_ BeneficiadoHumedo\#Proceso_de_ beneficiado_h\%C3\%BAmedo_del_caf\%C3\%A9

Ministerio de Fomento Industria y Comercio. Ley 368. [En línea]. Consultado [21, Abril, 2013]. Disponible en:http://www.mific.gob.ni/LinkClick.aspx?fileti cket $=2 Q$ sy4Frosio $\% 3 D \&$ tabid $=588$ \&language $=$ es-NI\%20Reglamentaci\%C3\%B3n\%20del\%20 caf\%C3\%A9 